\title{
Research and Verification of Key Techniques in the Simulation of Space Extremely Rapid Decompression in Millisecond
}

\author{
Junwei Wang $\mathbb{D}^{\mathbb{D}}$, Lei Zhang $\mathbb{D}^{D}$, Guohua Li, Ran Liu, Juan Ning, Xiao Han, and Xin He \\ Beijing Institute of Spacecraft Environment Engineering, Beijing 100094, China \\ Correspondence should be addressed to Junwei Wang; tobenol@126.com
}

Received 10 October 2020; Revised 9 February 2021; Accepted 20 March 2021; Published 5 April 2021

Academic Editor: Giovanni Palmerini

Copyright (C) 2021 Junwei Wang et al. This is an open access article distributed under the Creative Commons Attribution License, which permits unrestricted use, distribution, and reproduction in any medium, provided the original work is properly cited.

\begin{abstract}
The research of rapid decompression with its effect assessment and protection technology is the problem that must be faced by the future exploration projects such as near space exploration, deep space exploration, and long-term lunar or Mars base. A new reusable quick opening mechanism which can be opened in millisecond is designed to meet the testing requirement of ground simulator for extremely rapid decompression, and the testing results show that the quick opening mechanism can be opened within $0.1 \mathrm{~s}$. The mathematical formulation is also developed, and the comparisons with the results from the literature demonstrate its validity. The CFD simulation and the verification system are established for the airflow in the rapid decompression process under different opening degrees. The simulation results show that the effect of the opening on the decompression process is very obvious and the decompression time corresponding to $50 \%, 75 \%$, and $100 \%$ opening is $479.1 \mathrm{~ms}$, $320.7 \mathrm{~ms}$, and $290.1 \mathrm{~ms}$, respectively. The testing results also show a consistent trend which is $583 \mathrm{~ms}, 450 \mathrm{~ms}$, and $384 \mathrm{~ms}$, respectively, to reach the equilibrium state.
\end{abstract}

\section{Introduction}

The current research on the rapid decompression focuses on the aeronautics and astronautics field. The research emphasis in the aviation field mainly is the verification of design, performance, and reliability for aircraft and airborne equipment under high altitude decompression environment. In the space field, research institutions represented by NASA have carried out a lot of studies on the rapid decompression that may occur in the space environment, such as the space shuttle and the space station, and guided the design and verification of spacecraft, spacesuit, and Environmental Control and Life Support System (ECLSS) for astronaut [1-7].

The rarefied gas flow in space decompression process can be studied by approximate simplified calculation or numerical simulation. Eoffrey established a numerical model for the pressure drop process of exposed vacuum [8]. Pagani and Carrera developed a zero-dimensional mathematical formulation for rapid and explosive decompression analyses of pressurized aircraft. The numerical procedure based on Euler integration scheme had also been discussed for multicompartment aircraft analysis [9]. Bréard et al. modeled and ana- lyzed the sudden decompression of an airliner cockpit with a hardened cockpit door installed using the CFD code [10]. Gao et al. from Beijing University of Aeronautics and Astronautics put forward the technology of prevacuum chamber to realize the simulated rapid decompression and deduced the mathematical equation of the airflow balance between the prevacuum chamber and testing chamber combining with the flow conduction equation and gas thermodynamics theory [11].

Many kinds of facility have been built for the ground simulation of rapid decompression in China and other research institutions. The Johnson Space Center in the United States designed an additional chamber as a rapid decompression chamber next to its 20 -foot diameter thermal vacuum chamber and completed the product verification testing such as high-pressure tank and airbag [12]. The research institutions such as the Institute of Aviation Medicine and Astronaut Training Center in China have also built similar rapid decompression facility. The rapid decompression system of the Astronaut Training Center consists of the main chamber and the auxiliary chamber. The length of the cylinder of the main chamber is $3 \mathrm{~m}$, and its volume is 
about $50 \mathrm{~m}^{3}$. The length of the auxiliary chamber is $2 \mathrm{~m}$, and the volume is $12.5 \mathrm{~m}^{3}$. During the testing of rapid decompression, the main chamber is prevacuum chamber and a DN320mm vacuum pipeline is used for releasing channel with four DN150mm electromagnetic valves. The rapid decompression rate of the system is better than that of $13.3 \mathrm{kPa} / \mathrm{s}$. Yi Dongchen from the Institute of Aviation Medicine has developed a compound environment facility with the function of rapid decompression, which is used for the evaluation of aeronautic equipment and the scientific research training of aviation medicine. The quick opening mechanism adopted compressed air as the power, and the pneumatic power is converted to hydraulic power through the accumulator to push the motion of piston rod in hydraulic cylinder [13]. In cooperation with the Beijing Institute of Spacecraft Environmental Engineering, Harbin Institute of Technology completed a brand-new principle design of the quick opening mechanism, which is realized by utilizing a spring-based release mechanism to instantly convert large amounts of elastic potential energy into kinetic energy $[14,15]$.

Based on the investigation of the research status, considering the further improvement of the requirements for accurate simulation of space extremely rapid decompression, it is in urgent need of a reusable quick opening mechanism with high reliability that can be opened within the range of milliseconds to meet the research and verification requirements of space extremely rapid decompression process. The research has been presented in Section 2. The methods of calculation and numerical simulation also need further study in order to get more accurate results, which are discussed in Sections 3 and 4. The testing verification is shown in Section 5, and the conclusions are summarized at the end of the paper.

\section{Design of the Quick Opening Mechanism}

Quick opening mechanism is the key equipment for the ground simulation of extremely rapid decompression environment. The design of the mechanism mainly faces the following difficulties:

(1) Quick opening speed: for the extremely rapid decompression, the whole time is $0.1 \mathrm{~s}$ generally to finish the whole decompression process, so it requires that the mechanism should achieve the full opening within $0.1 \mathrm{~s}$ or even faster

(2) Vacuum sealing: the quick opening mechanism is installed between the high-pressure chamber and the low-pressure chamber. The mechanism should be able to withstand huge reverse pressure difference before the test, especially to the large quick opening mechanism

(3) Reusable and reliable: due to the huge pressure difference and the extremely fast opening speed, the parts of the quick opening mechanism will bear a great impact force, so the mechanism design should be with high reliability even after multiple uses

For the requirement of extremely rapid decompression environment on ground, a new type of reusable quick open- ing mechanism is designed in the paper which can achieve instantaneous open between the prevacuum chamber and testing chamber. The mechanism comprises a valve unit, a releasing unit, a closing unit, and an energy storage unit; the specific structure of which is shown in Figure 1.

When the mechanism is closing, the traction cylinder of the closing unit moves downward to push the ejector rod and the trailed disc moving downward in a straight line. Meanwhile, the spring of the energy storage unit achieves stretching energy storage. After the traction cylinder moves downward in place, the cover plate can be rotated to the closed position so that the bearing of the releasing unit is pressed above the cover plate. At this time, the bearing, cover plate, ejector rod, and sealing plate are transferred to the downward force to realize the closure of the mechanism. The pretightening force of sealing plate can be adjusted by rotating the hand wheel until the mechanism is completely closed and then lift the traction cylinder of the closing unit upward to its original position. When the mechanism needs to be opened, the electromagnetic actuator drives the bearing to retract at tremendous speed so that the bearing no longer exerts pressure on the cover plate. At this time, the ejector rod and the sealing plate lose the pressure of the cover plate. Due to the superposition of atmospheric pressure on the sealing plate and the stretching energy storage of springs, the sealing plate can complete the upward movement and achieve open in milliseconds. When the trailed disc moves to the damping block, the resistance stops to complete the opening action of the whole mechanism.

The strength of the mechanism was analyzed by finite element method using ANSYS. The input parameters of the simulation are shown in Table 1, and the force analysis of the quick opening mechanism is shown in Figure 2. The results indicated that the von Mises stress did not exceed the maximum tension value, and the structure of the mechanism met the safety requirements.

The prototype of the mechanism is shown in Figure 3. Before the testing of the rapid decompression, two connecting flanges of the quick opening mechanism are, respectively, installed on the testing chamber and prevacuum chamber. Close the mechanism according to the above operation sequence, pump the testing chamber and prevacuum reserve chamber to the required pressure, and then open the quick opening mechanism to achieve the rapid decompression.

The designed quick opening mechanism has the following beneficial characteristics:

(1) Due to the superposition of atmospheric pressure on the sealing plate and the stretching energy storage of springs, the mechanism can be opened within the magnitude of milliseconds

(2) In addition, the strength can be changed through the replacement of spring strength subsequently, so as to achieve the function of adjusting the opening time

(3) The welded bellows are used to complete the sealing of shaft, and the whole mechanism has no dynamic sealing structure 


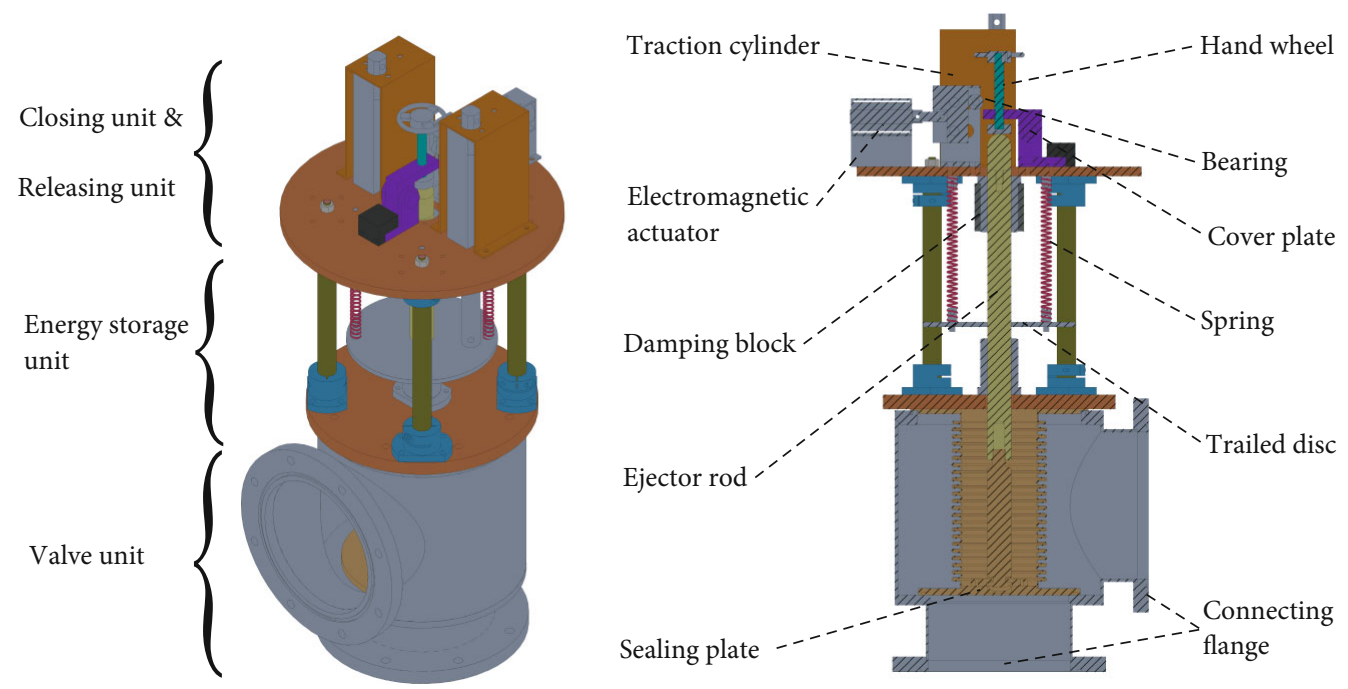

FIGURE 1: The specific structure of quick opening mechanism.

TABLE 1: List of input parameters.

\begin{tabular}{lc}
\hline Input parameters & Value \\
\hline Atmospheric pressure & $101.3 \mathrm{kPa}$ \\
Pressure of O-ring & $200.0 \mathrm{kPa}$ \\
Vacuum pressure & $1.0 \mathrm{kPa}$ \\
Traction of single spring & $100 \mathrm{~N}$ \\
Friction coefficient & 0 \\
Mesh quantity & 1225469 \\
\hline
\end{tabular}

(4) The cylinder is equipped to complete the auxiliary closing of the mechanism, and electromagnetic actuator is used to complete the opening action of the mechanism with high degree of automation

(5) The linear motion mode of the sealing plate of the mechanism is more reliable, simpler in structure, and more powerful in function

\section{Mathematical Model}

Rapid decompression is a typical problem of inflating and deflating for rigid chambers. The process of inflating and deflating is rapid, and the heat exchange between the system and the outside world can be ignored. The temperature variation and the nonuniformity of pressure and temperature of each module are also ignored. The calculation formula of airflow through the quick opening mechanism is

$$
\dot{m}=\frac{C_{d} A p_{1}}{\sqrt{R T_{1}}} f\left(p_{1}, p_{2}\right),
$$

$$
f\left(p_{1}, p_{2}\right)= \begin{cases}\sqrt{\frac{2 \gamma}{\gamma-1}\left[\left(\frac{p_{2}}{p_{1}}\right)^{2 / \gamma}-\left(\frac{p_{2}}{p_{1}}\right)^{(\gamma+1) / \gamma}\right]}, & \frac{p_{2}}{p_{1}}>\left(\frac{2}{\gamma+1}\right)^{\gamma /(\gamma-1)}, \\ \sqrt{\gamma\left(\frac{2}{\gamma+1}\right)^{(\gamma+1) /(\gamma-1)}}, & \frac{p_{2}}{p_{1}} \leq\left(\frac{2}{\gamma+1}\right)^{\gamma /(\gamma-1)} .\end{cases}
$$

The calculation of the pressure and temperature of the testing chamber can be obtained from the first law of thermodynamics and the Ideal Gas Equation as follows.

The pressure variation formula of the testing chamber

$$
\frac{d p_{1}}{d t}=-\frac{\gamma R T_{1} \dot{m}_{1}}{V_{1}}
$$

The temperature variation formula of the testing chamber

$$
\frac{T_{1}}{T_{1,0}}=\left(\frac{p_{1}}{p_{1,0}}\right)^{(\gamma-1) / \gamma} .
$$

The lumped parameter method was used to model the connecting pipeline for decompression, and the heat transfer of gas flow in the process was not considered. Assuming that the velocity, pressure, and temperature of the connecting pipeline were uniformly distributed, the calculation formula of the pressure variation with time of the connecting pipeline in the process of decompression was as follows:

$$
\frac{d p_{2}}{d t}=\frac{\gamma R T_{1}\left(\dot{m}_{1}-\dot{m}_{2}\right)}{V_{2}}
$$

where $m_{1}$ and $m_{2}$ are the mass flow rates of the inflow and outflow pipelines, respectively.

where 


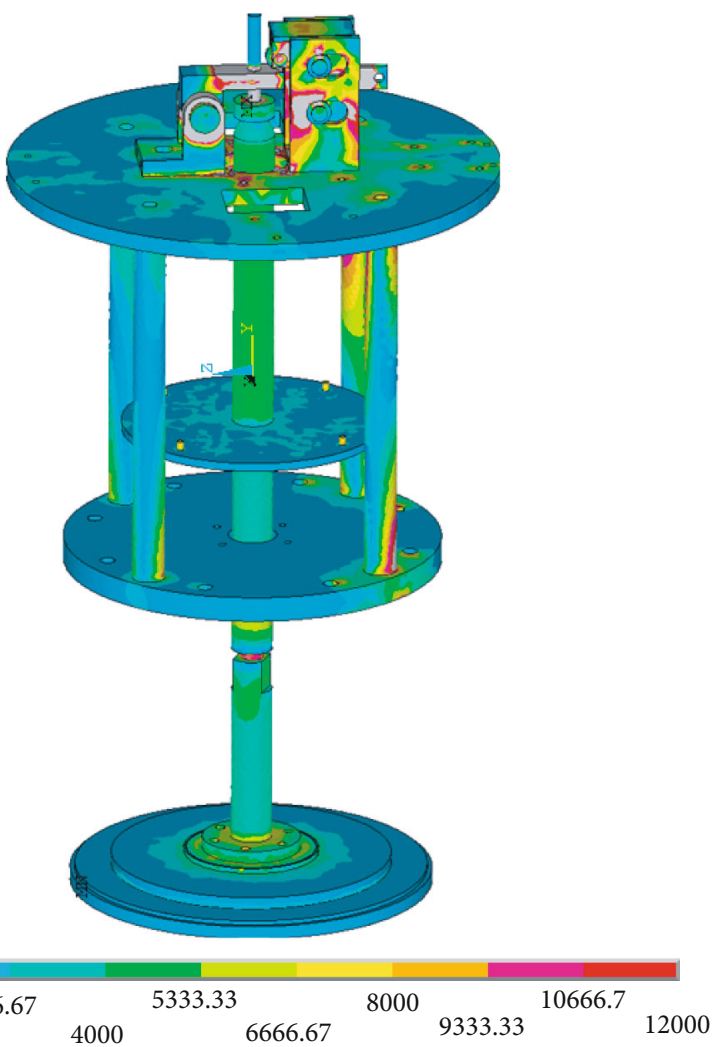

Figure 2: The cloud map of von Mises stress for the mechanism.

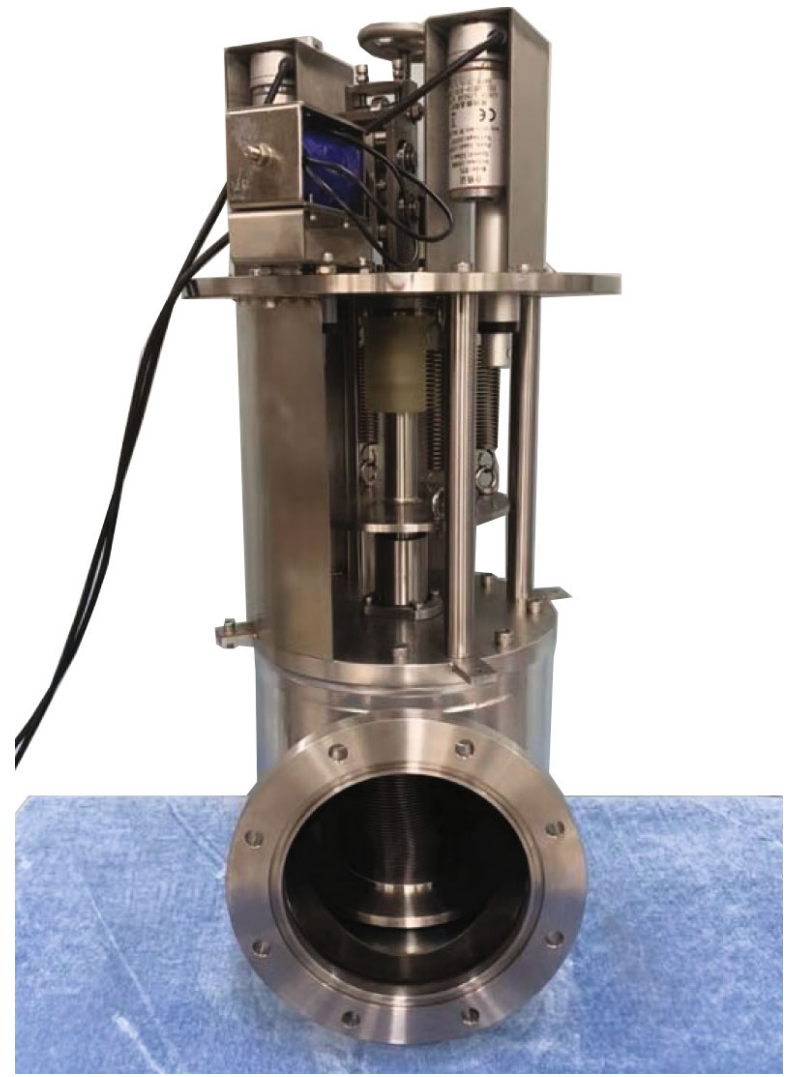

FIgURE 3: The experimental prototype of the mechanism. 


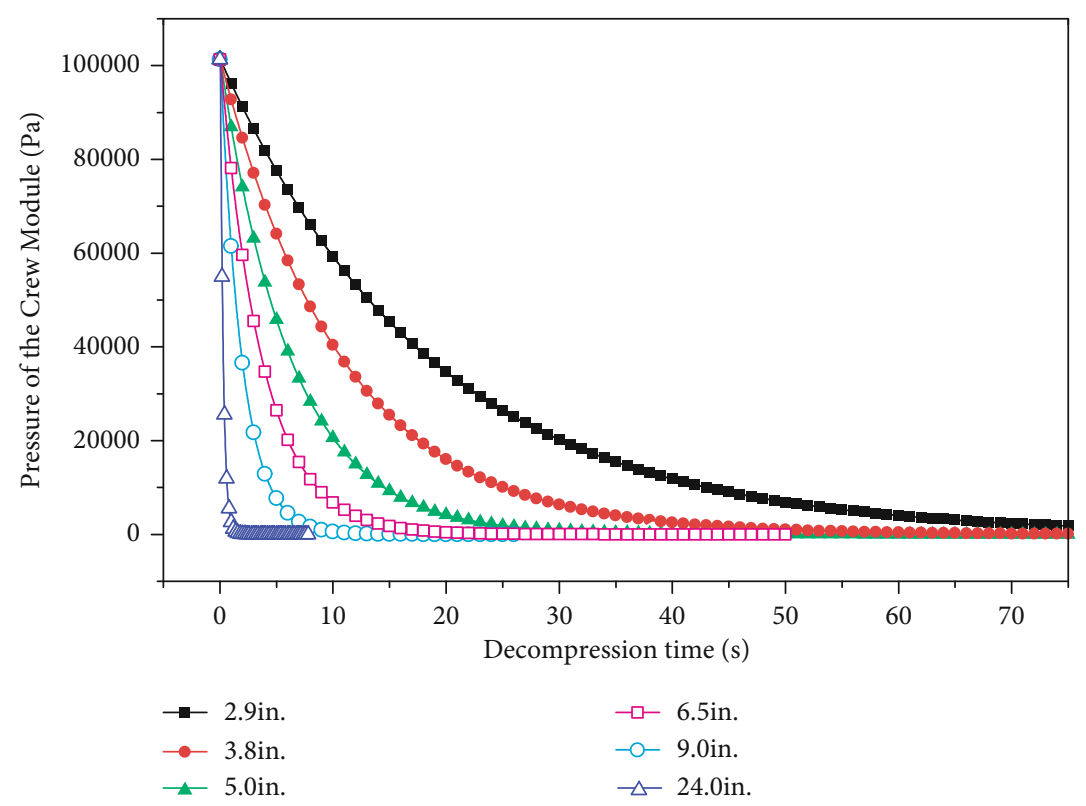

FIgURE 4: The decompression time under different hole size for Crew Module.

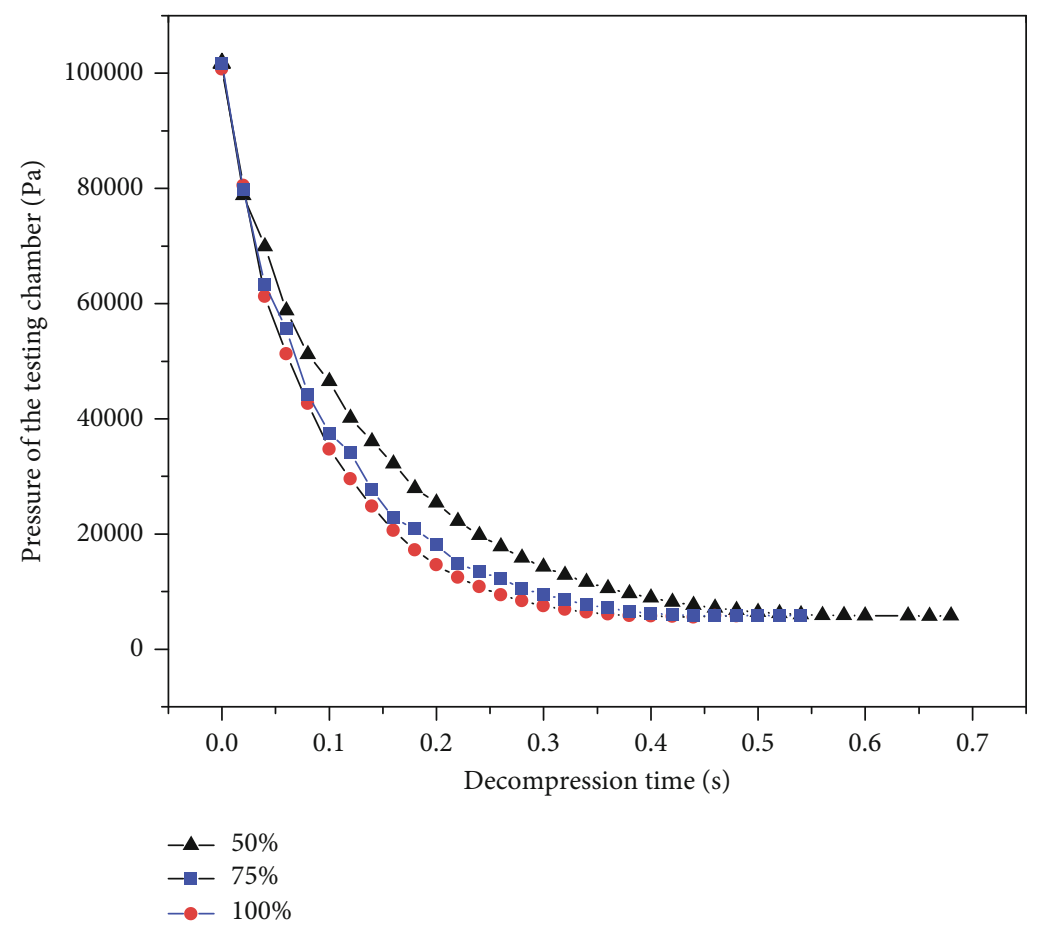

FIGURE 5: The pressure variation of testing chamber under different openings.

Similarly, the calculation formula of the pressure and temperature of the prevacuum chamber can be obtained as follows.

The pressure variation formula of the prevacuum chamber

$$
\frac{d p_{3}}{d t}=\frac{\gamma R T_{1} \dot{m}_{2}}{V_{3}}
$$

The temperature variation formula of the prevacuum chamber

$$
\frac{T_{3, t+1}}{T_{3, t}}=\frac{\gamma}{\left(T_{3, t} / T_{1, t+1}\right)+\left(\gamma-\left(T_{3, t} / T_{1, t+1}\right)\right)\left(p_{3, t} / p_{3, t+1}\right)} .
$$

The rapid decompression process can be calculated and analyzed through the above calculation formula. This paper 


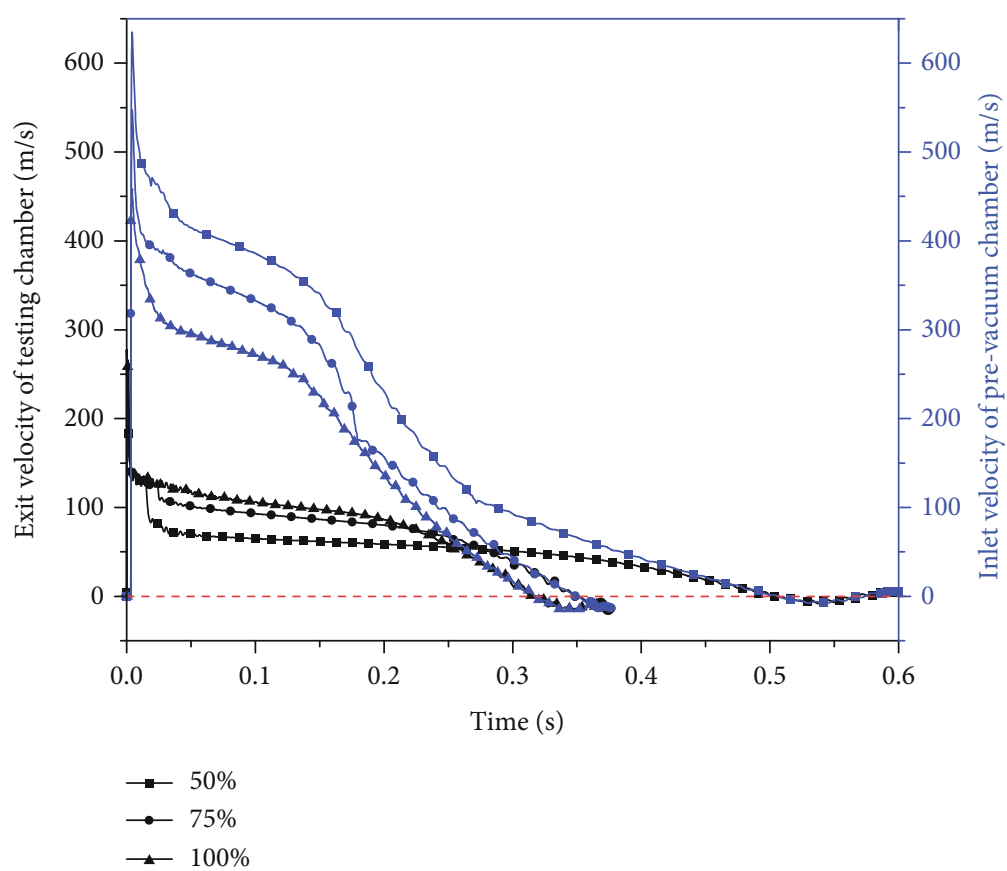

(a)

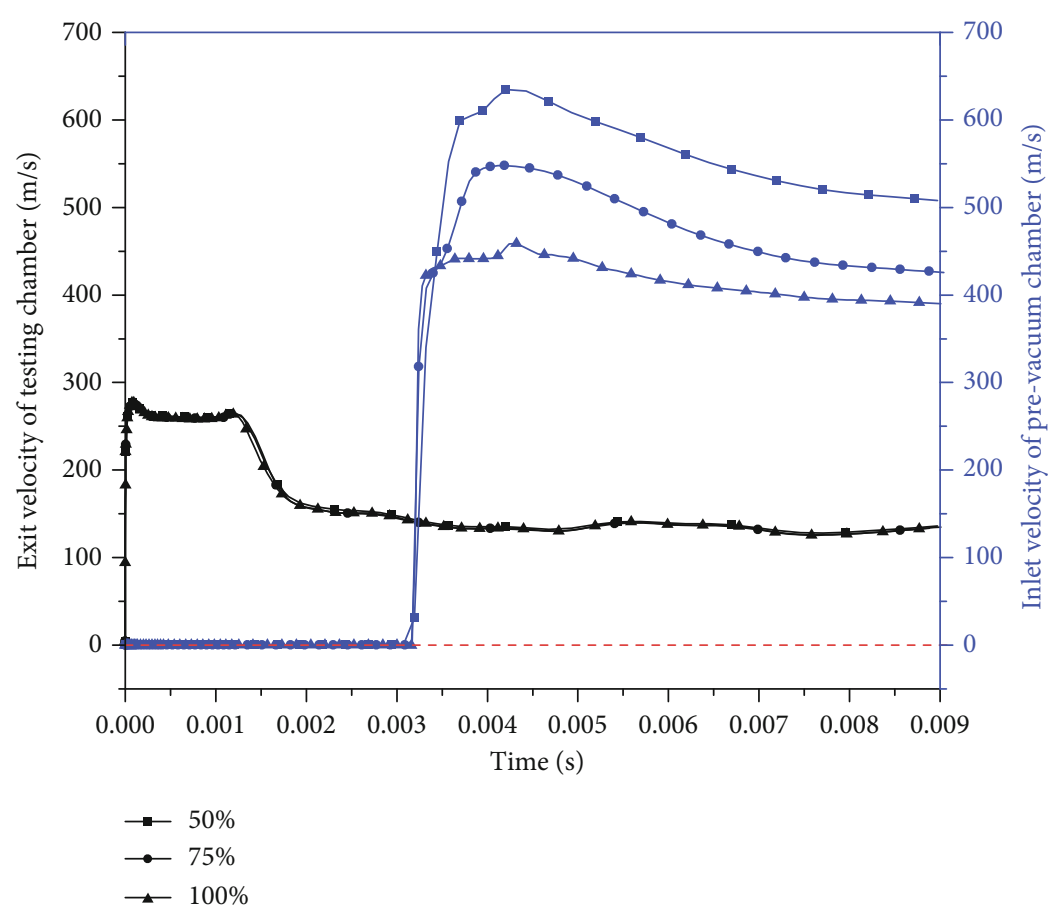

(b)

Figure 6: The change of average velocity under different openings.

verifies the validity of the calculation through similar literature cases. In reference [16], NASA studied the safety assessment of the next-generation Multipurpose Crew Vehicle (MPCV) under the different decompression processes and summarized the estimated time for Crew Module depressurization as a function of the effective hole size. The formula in this paper is used to recalculate and verify the decompression time under the same conditions with a $550 \mathrm{ft}^{3}$ cabin volume at standard atmospheric pressure. The specific calculation results are shown in Figure 4. The comparisons with the results from the literature demonstrate the validity of the calculation method, which can be also applied, with no lack of accuracy, to the decompression analysis of spacecraft.

\section{CFD Simulation}

In order to study the airflow characteristics in the rapid decompression process more intuitively, the FLUENT which 


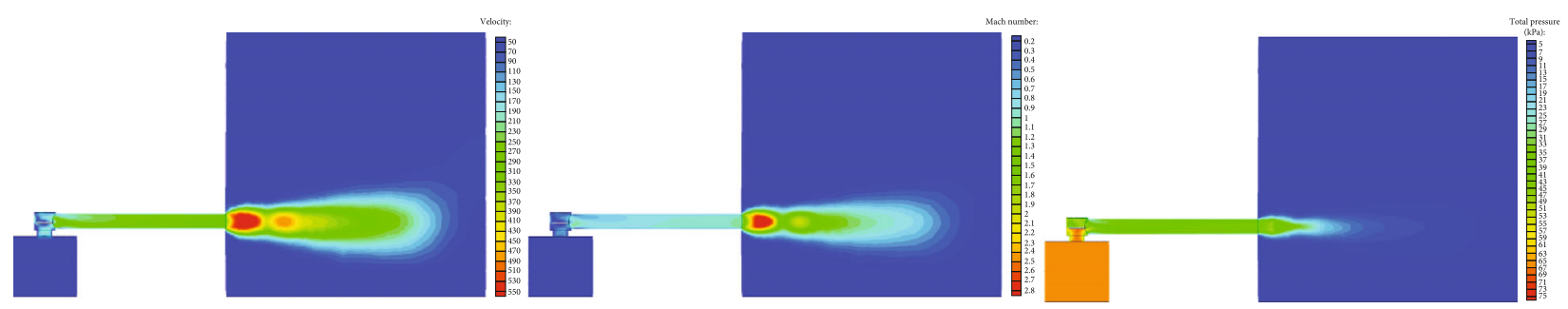

(a) The distribution of flow field under $100 \%$ opening of gate valve $(30 \mathrm{~ms})$

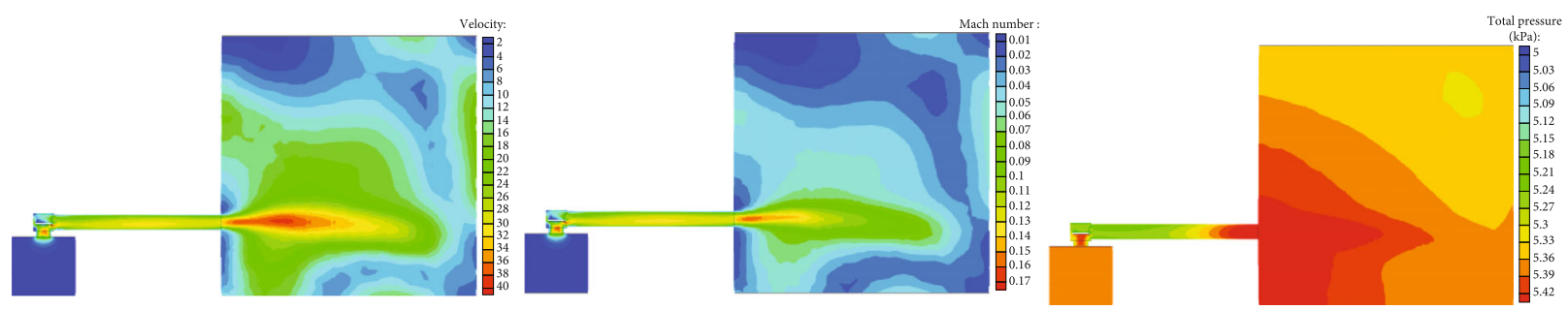

(b) The distribution of flow field under 100\% opening of gate valve (290 ms)

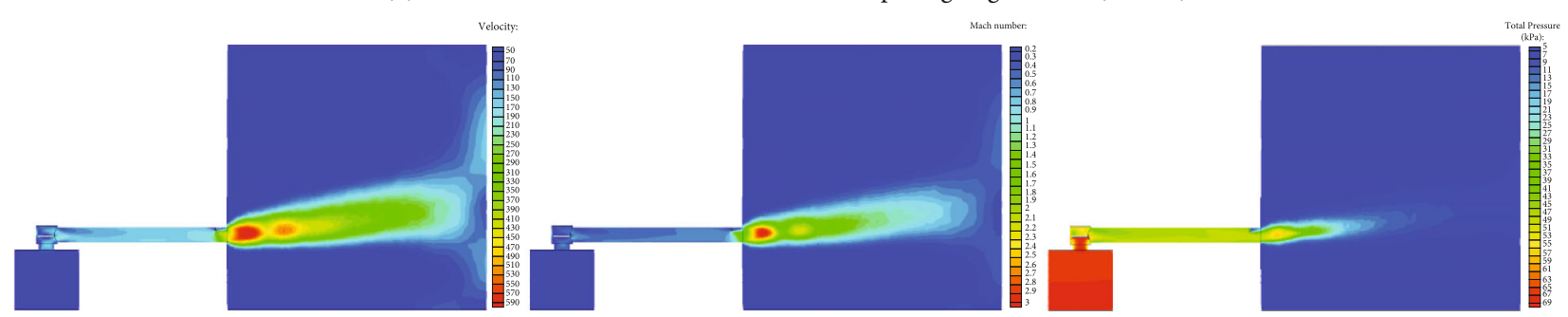

(c) The distribution of flow field under $75 \%$ opening of gate valve $(30 \mathrm{~ms})$

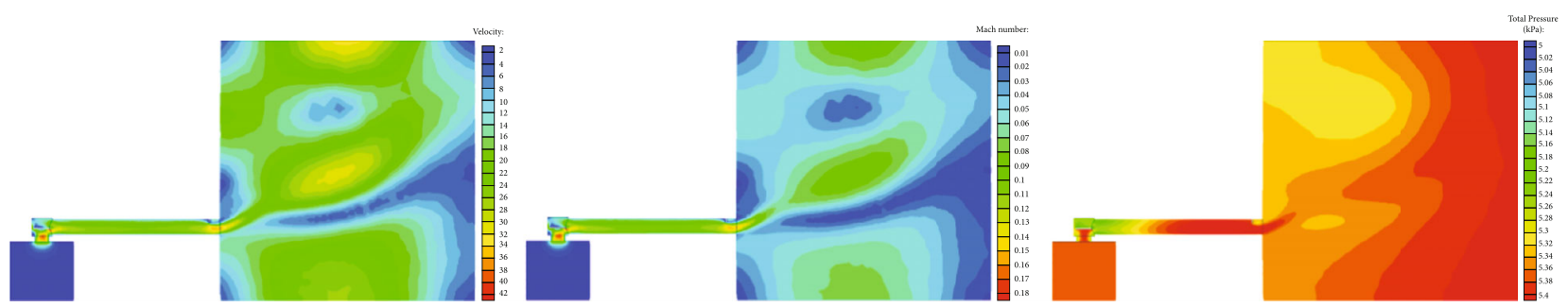

(d) The distribution of flow field under 75\% opening of gate valve (321 ms)

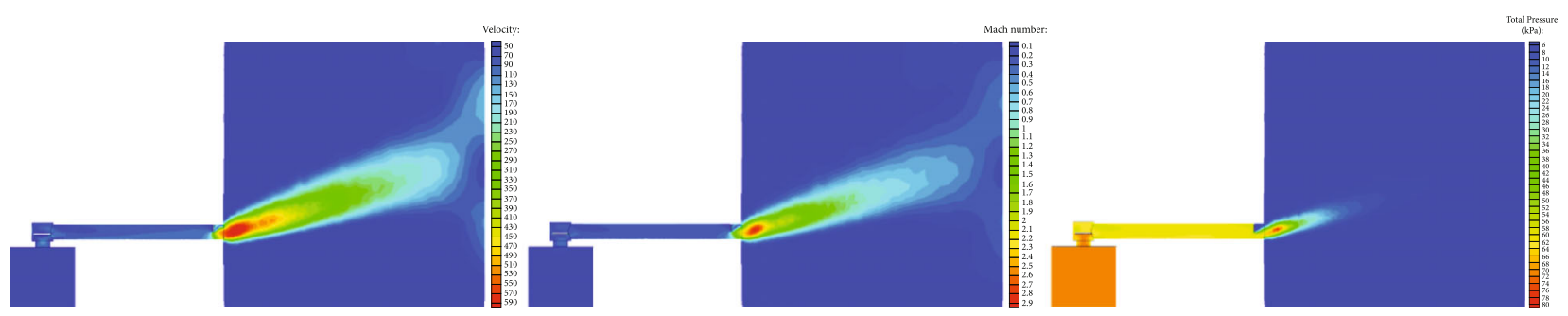

(e) The distribution of flow field under $50 \%$ opening of gate valve $(30 \mathrm{~ms})$

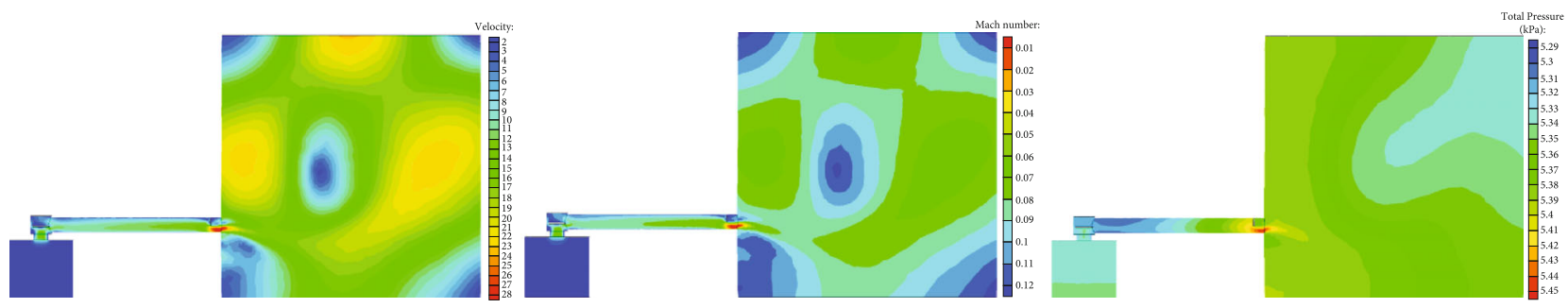

(f) The distribution of flow field under 50\% opening of gate valve ( $479 \mathrm{~ms}$ )

FIGURE 7: The distribution of flow field in rapid decompression process (the left is the velocity distribution, the middle is the Mach number distribution, and the right is the total pressure distribution). 


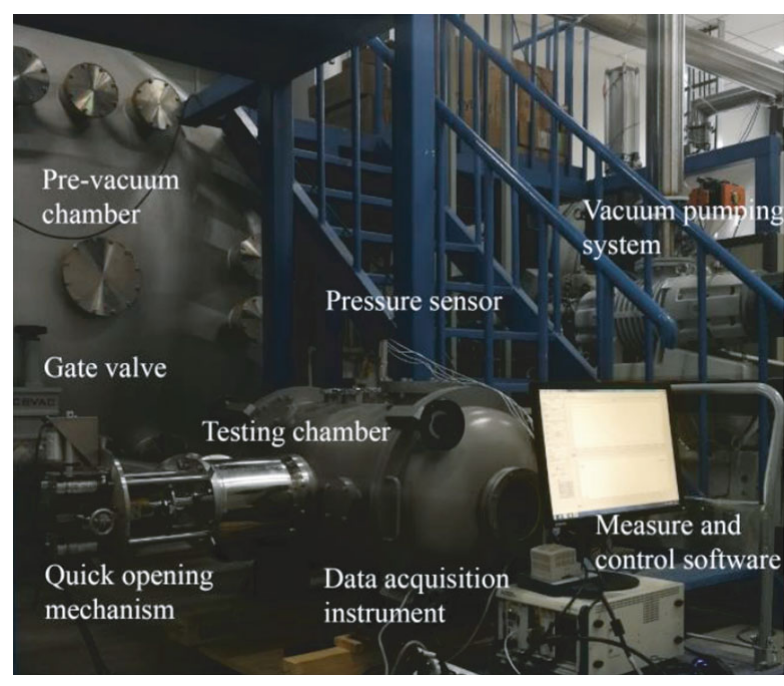

FIGURE 8: The verification system.

is a commercial CFD software is used to simulate the pressure changes in chambers. The model was divided into two chambers with a volume of $0.2 \mathrm{~m}^{3}$ and $14 \mathrm{~m}^{3}$, respectively. The DN150 decompression pipeline with a length of $1 \mathrm{~m}$ was equipped with a quick opening mechanism and a DN150mm vacuum gate valve that can be opened under $100 \%, 75 \%$, and $50 \%$ opening, respectively. The details such as the sealing plate of the mechanism and the valve plate of the gate valve also are modeled considering the flow coefficient to get the better simulation accuracy.

The model structure discretizes the calculation area with polyhedral unstructured grids, sets boundary layer grids for the inside of the pipeline. Discrete RANS (Reynolds Average Navier-Stokes) equation based on finite volume method and $k$ - $\omega$ turbulence model is adopted. The initial value of the testing chamber pressure is $101.325 \mathrm{kPa}$, and the initial value of the prevacuum chamber pressure is set as $4 \mathrm{kPa}$.

4.1. The Pressure Change of Testing Chamber. The variation trend of pressure in the testing chambers is shown in Figure 5, where the pressure is the absolute pressure at the geometric center point of each chamber. It can be seen that different valve openings have a significant influence on the decompression process, and the smaller the opening is, the more obvious it is. Decompression time corresponding to $50 \%, 75 \%$, and $100 \%$ opening degree is $479.1 \mathrm{~ms}, 320.7 \mathrm{~ms}$, and $290.1 \mathrm{~ms}$, respectively.

4.2. The Velocity Change of Testing Chamber. More details can be obtained through analysis of decompression velocity. Take the average velocity of the exit section of the testing chamber and the inlet section of the prevacuum chamber, and observe the variation trend of these two average velocities, as shown in Figure 6, where Figure 6(a) is the overall variation trend and Figure $6(\mathrm{~b})$ is the velocity variation detail of the first $9 \mathrm{~ms}$. The line with the same symbol in the figure represents the working condition of the valve under the same opening. The black line is the average outlet velocity of the testing chamber, the blue line is the average inlet velocity of the prevacuum chamber, and the red dotted line is zero.

As shown in Figure 6(a), the smaller the valve opening is, the corresponding exit velocity of testing chamber is smaller, and the inlet velocity of prevacuum chamber is greater. The reason for this is that the baffle of valve increases the flow resistance, increases the expansion ratio, and reduces the entrance density of the prevacuum chamber, which leads to the decrease of the outlet velocity of the testing chamber and the increase of the inlet velocity of the prevacuum chamber at the same time. All the curves on the right of the figure drop below the red dotted line and show negative values, indicating that there is a phenomenon of reverse flow at this time, and there is a slight iteration when the flow reaches the equilibrium state. It can be seen from Figure 6(b) that the flow velocity curve at the outlet of the testing chamber almost coincides at the initial stage. This is due to the fact that the back of the quick opening mechanism in the pipeline is in supersonic flow, and the flow state is only related to the parameters of inlet flow, and the opening of the gate valve has no influence on it. The inlet velocity of the prevacuum chamber remains zero at the first $3 \mathrm{~ms}$. This is because the incoming flow propagates in the pipeline in the form of shock wave. However, it reaches a high velocity immediately with the highest points being $634.8 \mathrm{~m} / \mathrm{s}, 547.7 \mathrm{~m} / \mathrm{s}$, and $458.6 \mathrm{~m} / \mathrm{s}$, respectively.

4.3. The Distribution of Flow Field. The opening of gate valve has an obvious influence on the flow field. Figure 7 shows the distribution of flow field under the different opening conditions. It can be seen that the sealing plate of the quick opening mechanism bears the impact of air flow, and there is a certain pressure difference on both sides. However, the total pressure drop of the pipeline is close to the ideal state and does not increase significantly. There is turbulence around the quick opening mechanism, and the flow field is complex. The flow is fully developed after a long pipeline. Under the condition of $75 \%$ opening of the gate valve, there is a significant pressure difference between the front and back of the valve and a significant change in the direction of jet flow and the flow field of the gate valve is obviously influenced. The influence of flow field is more obvious under the condition of $50 \%$ opening. The pressure difference before and after the gate valve becomes the most important pressure drop inside the pipeline. The gas appears obvious step-down expansion here, and the deflection of jet direction is very obvious.

\section{Testing Verification}

The verification system was established for the rapid decompression process, which is shown in Figure 8. The main parameters of the system are the same as the numerical model.

Under atmospheric pressure, a high-speed camera was used to monitor the quick opening mechanism, and the mechanism could be opened within $0.1 \mathrm{~s}$. Tests were carried out for the valves with different opening degrees of $50 \%$, 

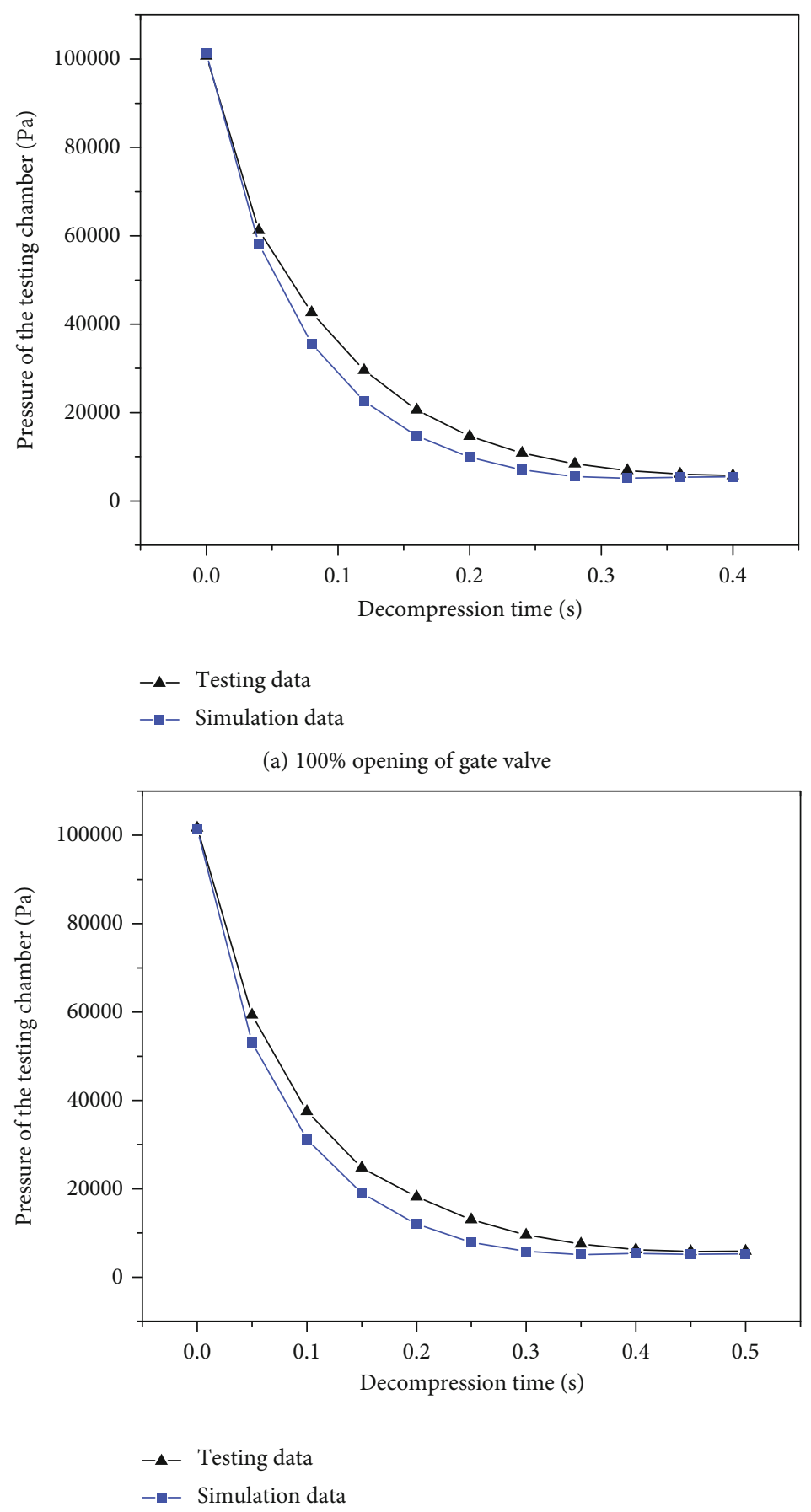

(b) $75 \%$ opening of gate valve

Figure 9: Continued. 


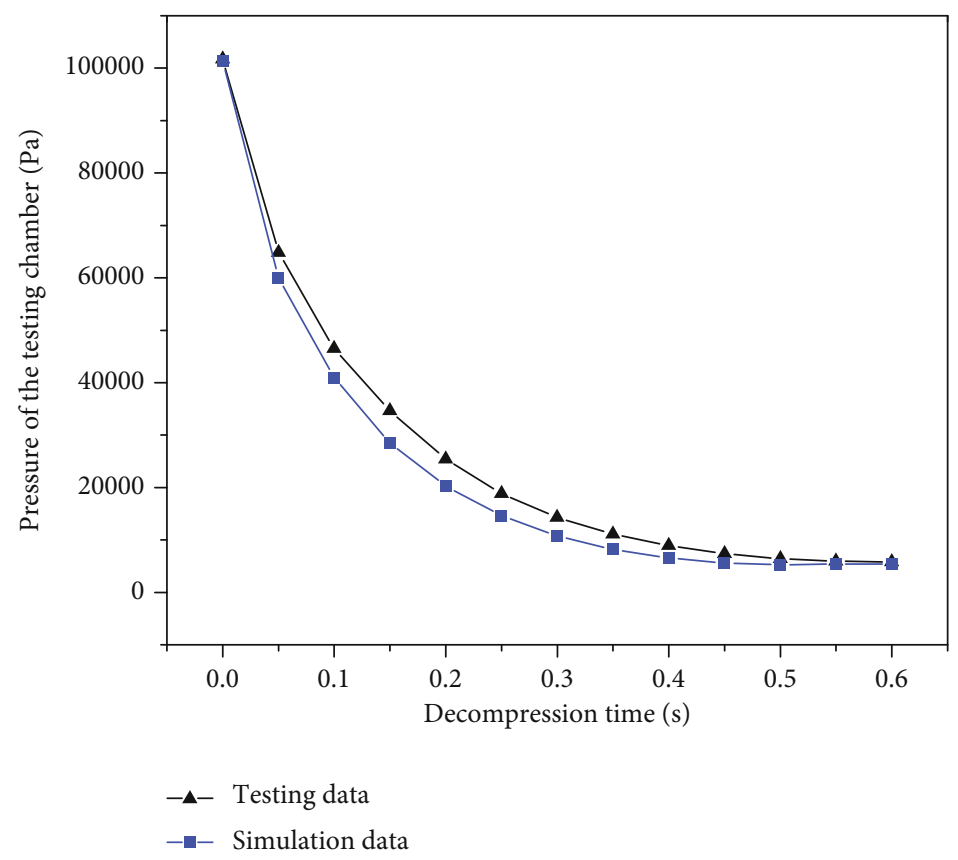

(c) $50 \%$ opening of gate valve

FIGURE 9: Comparison and verification between testing and simulation data of the testing chamber.

$75 \%$, and $100 \%$, respectively, which needs $583 \mathrm{~ms}, 450 \mathrm{~ms}$, and $384 \mathrm{~ms}$, respectively, to reach the equilibrium state.

The comparison of testing results and numerical simulation under three different opening degrees of gate valve is shown in Figure 9. The two trends are very similar, and the actual rapid decompression process takes longer time than the numerical simulation because the airflow cannot be depressurized fully during valve opening. There are also some fluctuations in the testing data which is because of a slight oscillation of the sealing plate after the quick opening mechanism is open.

\section{Conclusion}

The key techniques of the ground simulation for space extremely rapid decompression are studied and verified, and the following conclusions are drawn:

(1) A new type of reusable quick opening mechanism with high reliability is designed to realize the extremely rapid decompression. The mechanism verified by high-speed camera can be opened within $0.1 \mathrm{~s}$

(2) The mathematical formulation is also developed for rapid decompression, and the comparisons with the results from the literature demonstrate the validity of the calculation method

(3) The numerical model is established to study the flow characteristics in the rapid decompression process. The opening of the decompression pipeline is adjusted through the gate valve. The results show that the effect of the opening is very obvious. The decompression time corresponding to $50 \%, 75 \%$, and $100 \%$ opening is $479.1 \mathrm{~ms}, \quad 320.7 \mathrm{~ms}$, and $290.1 \mathrm{~ms}$, respectively

(4) The opening also has a significant influence on the velocity of decompression. The smaller the opening is, the smaller the outlet flow velocity of the corresponding testing chamber will be, while the inlet flow velocity of the prevacuum chamber will be larger. When the flow reaches the equilibrium state, there will be slight iteration

(5) The verification system is established for the rapid decompression process. The two trends are very similar, and the actual rapid decompression process takes longer time than the numerical simulation with the reason of mechanism opening time. There are some fluctuations in the testing data which is because of a slight oscillation after the quick opening mechanism is open

\section{Data Availability}

The data used to support the findings of this study are available from the corresponding author upon request.

\section{Conflicts of Interest}

There are no conflicts of interest to declare.

\section{Acknowledgments}

The authors acknowledge the financial support provided by the Independent Research and Development Project of BISEE (Project No. YFKT-201909260034). 


\section{References}

[1] N. E. Daidzic and M. P. Simones, "Aircraft decompression with installed cockpit security door," Journal of Aircraft, vol. 47, no. 2, pp. 490-504, 2010.

[2] K. Curry and K. Prokhorov, "International Space Station (ISS) responses to rapid depressurization," in Proceedings of the 32nd International Conference on Environmental Systems, 2002-01-2493, San Antonio, Texas, July 2002.

[3] J. D. Pratt, "Rapid decompression of pressurized aircraft fuselages," Journal of Failure Analysis and Prevention, vol. 6, pp. 70-74, 2006.

[4] J. F. Lu, L. Li, and L. Chen, "Study on the decompression time of the hypobaric rapid decompression chamber," International Journal of Heat and Technology, vol. 33, no. 2, pp. 75-78, 2015.

[5] G. Cable, "In-flight hypoxia incidents in military aircraft: causes and implications for training," Aviation, Space, and Environmental Medicine, vol. 74, no. 2, pp. 169-172, 2003.

[6] J. Bai, X. Chen, J. Yang, and S. Yang, "Simulation of aircraft cabin pressure loss," Journal of Civil Aviation University of China, vol. 32, no. 6, pp. 1-6, 2014.

[7] X. Song and B. Zai, "Low pressure test standard and test technical analysis," Environmental Technology, vol. 6, pp. 94-97, 2014.

[8] A. Eoffrey, "Mathematical model research of human exposure to vacuum," Journal of the British Interplanetary Society, vol. 29, no. 2, pp. 148-154, 2008.

[9] A. Pagani and E. Carrera, "Gas dynamics of rapid and explosive decompressions of pressurized aircraft including active venting," Advances in Aircraft and Spacecraft Science, vol. 3, no. 1, pp. 77-93, 2016.

[10] C. Bréard, D. Lednicer, N. Lachendro, and E. Murvine, "A CFD analysis of sudden cockpit decompression," in $42 n d$ AIAA Aerospace Science Meeting and Exhibit, AIAA-20040054, Reno, USA, January 2004.

[11] H. Gao, M. Liu, and J. Wang, "Novel technique to rapidly pump spacecraft cabin with negatively pressured cabin and its theoretical basis," Journal of Vacuum Science and Technology, vol. 33, no. 12, pp. 1191-1198, 2013.

[12] S. E. Jacobs, "Quantification of the dynamic pressure response in a pressure suit during a rapid cabin decompression," in $43 \mathrm{rd}$ International Conference on Environmental Systems, AIAA 2013-3397, Vail, CO, July 2013.

[13] D. Yin, H. Xiao, and B. Zhang, "Development of experiment chambers of complex low-pressure environment," Chinese Medical Equipment Journal, vol. 42, no. 1, pp. 6-12, 2011.

[14] L. Zhang, X. Han, X. B. Zhang, and J. H. Yan, "Door-triggering mechanism for large-scale rapid-decompression experiments," International Journal of Aerospace Engineering, vol. 2020, Article ID 6841651, 9 pages, 2020.

[15] X. Han, W. Leng, and S. Z. Lv, "Design of fast pressure relief mechanism for fast pressure relief environment simulation equipment," Spacecraft Environment Engineering, vol. 36, no. 4, pp. 387-392, 2019.

[16] M. J. Sargusingh, "MPCV flight suit performance after an uncontrolled crew cabin depressurization event," in 42nd International Conference on Environmental Systems, AIAA 2012-3644, San Diego, California, July 2012. 